THEORETICAL REVIEW

\title{
Epilepsy as a derailment of sleep plastic functions may cause chronic cognitive impairment - A theoretical review
}

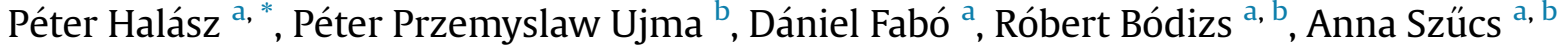 \\ ${ }^{a}$ National Institute of Clinical Neurosciences, Amerikai út 57, Budapest, H-1145, Hungary \\ b Semmelweis University, Institute of Behavioral Sciences, Nagyvárad tér 4, Budapest, H-1089, Hungary
}

\section{A R T I C L E I N F O}

\section{Article history:}

Received 8 July 2018

Received in revised form

31 December 2018

Accepted 21 January 2019

Available online 10 February 2019

\section{Keywords:}

Sleep-related epilepsies

Cognitive harm

Interictal epileptic activity

Sleep slow waves

Spindles

Mesiotemporal epilepsy

Epileptic encephalopathies

Age dependent childhood focal epilepsies

Centrotemporal spikes

Rolandic epilepsy

\begin{abstract}
S U M M A R Y
We report on a peculiar way of chronic cognitive impairment associated with interictal epileptic activity during NREM sleep. We review three major groups of epilepsy: mesiotemporal epilepsy (MTLE) involving the epileptic derailment of the hippocampal declarative memory system; childhood developmental epileptic encephalopathies; and the spectrum disorders of the perisylvian communication network with the centrotemporal spike phenomenon, overarching child- and adulthood epilepsies, totaling up the majority of epilepsies in childhood.

We outline high impact research-lines on the cognitive harm of epilepsy; causing specific or global cognitive decline through its interference with sleep plastic functions.

We highlight the key role of interictal activity in the development of cognitive impairment and the fact that we are unarmed against this harm, antiepileptic pharmaco-therapy being ineffective against the interictal process marked by spikes and high frequency oscillations.
\end{abstract}

(ㄷ) 2019 Published by Elsevier Ltd.

\section{Introduction}

Cognitive impairment and epilepsy

The cognitive impairment of epileptic patients has multiple origins. In this review, we do not deal with structural brain lesions underlying epilepsies and disregard the effect antiepileptic drugs on cognitive functions, rather, our focus is the cognitive harm caused by epileptic disorder itself.

Epilepsy research has provided convincing proofs on the existence of postictal cognitive deficits depending on the duration, localization and extension of seizures [1]. The cognitive impairment related to interictal epileptic discharges (IEDs) is less clear [2].

First Colin Binnie raised and demonstrated in several papers the instant cognitive harm (transient cognitive impairment, $\mathrm{TCI}$ ) of centrotemporal spikes (CTS) in Rolandic Epilepsy (RE) and of bilateral spike-waves (SW) in idiopathic generalized epilepsy [3,4];

\footnotetext{
* Corresponding author. Lotz K. str. 18, 1026, Budapest, Hungary.

E-mail address: Halasz35@gmail.com (P. Halász).
}

making clinicians wonder whether the frequent spiking in idiopathic focal childhood epilepsies (IFCE) needed treatment for preventing cognitive decline. While RE patients' transient cognitive signs apparently related to spiking supported this concept, the lack of cognitive impairment in their relatives carrying CTS made it ambiguous. The research on TCI had serious limitations. It assessed the instantaneous cognitive change associated to one IED only and, raised the chronic cognitive harm of IEDs just theoretically.

The coupling and interference of IEDs with plastic sleep functions shed special light on the chronic cognitive impairment associated to epilepsies [5]. These data suggest that beyond structural hippocampal sclerosis, an important functional factor - sleeprelated spiking-contributes to the cognitive loss in mesiotemporal lobe epilepsy (MTLE).

Thence the link between memory disturbances and hippocampal spiking during sleep became clear in MTLE [6-8] and the association of cognitive decline with the sleep-activation of IEDs in epileptic encephalopathy children has been scrutinized [9-14]. Both lines of research provided strong evidence on the interference of IEDs with sleep plastic functions occurring during NREM sleep. 


\begin{tabular}{|c|c|c|c|}
\hline \multirow{2}{*}{\multicolumn{2}{|c|}{ List of abbreviations }} & \multirow{3}{*}{$\begin{array}{l}\text { LTP } \\
\text { MTLE } \\
\text { PS }\end{array}$} & \multirow{3}{*}{$\begin{array}{l}\text { Long-term potentiation } \\
\text { Mesial temporal lobe epilepsy } \\
\text { Panayiotopoulos syndrome }\end{array}$} \\
\hline & & & \\
\hline CA1, 2 & Cornu Ammonis regions & & \\
\hline CTS & Centrotemporal spike & \multicolumn{2}{|c|}{ HFO with $250-500 \mathrm{~Hz}$ Pathological (epileptic) HFO } \\
\hline CAP & Cyclic alternating pattern & PN & Perisylvian cognitive network \\
\hline ESES & Electrical status epileptic in sleep & \multicolumn{2}{|c|}{ HFO with $100-250 \mathrm{~Hz}$ Physiological HFO } \\
\hline EE & Epileptic encephalopathy & \multicolumn{2}{|c|}{$80-250 \mathrm{~Hz}$ oscillations Ripples } \\
\hline \multicolumn{2}{|c|}{$250-500 \mathrm{~Hz}$ Fast ripples } & PN & Perisylvian cognitive network \\
\hline \multicolumn{2}{|c|}{ HFO $(80-500 \mathrm{~Hz})$ High frequency oscillations } & RE & Rolandic epilepsy \\
\hline \multirow[t]{2}{*}{ IFCE } & Idiopathic focal childhood epilepsies = perisylvian & SPW-R & Sharp wave ripple complex \\
\hline & network epilepsies & SW & Spike wave pattern \\
\hline ED & Interictal epileptic discharge & $\mathrm{TCI}$ & Transient cognitive impairment \\
\hline KS & Landau-Kleffner syndrome & & \\
\hline
\end{tabular}

The most instrumental studies dealt with three major groups of epilepsies:

1) MTLE, the most frequent adulthood epilepsy;

2) The spectrum disorders of the perisylvian epileptic network (PN) constituted by the most frequent focal/regional agedependent childhood epilepsies;

3) Epileptic encephalopathies including developmental childhood conditions.

We review below the mechanisms of cognitive impairment caused by IEDs in these groups of epilepsies.

\section{The hippocampo-frontal dysfunction in MTLE impairs declarative memory}

The hippocampo-frontal memory system strongly associates to NREM sleep. The active systems consolidation theory [13] states that memory traces initially stored in hippocampal circuits are transferred to neocortical networks via the interplay of NREM sleep-related electroencephalographic (EEG) components as slow waves, spindles and hippocampal sharp wave ripples (SPW-Rs).

SPW-R is a robust, far-reaching population episode, the most synchronized event of the mammalian brain [15], elevating the excitability of the hippocampus and connected structures [16-19]. It occurs in isolated hippocampal slices as well. The ripple is a high frequency ( $200 \mathrm{~Hz}$ in animals, $150 \mathrm{~Hz}$ in humans) event of the cornu ammonis (CA)1 pyramidal layer of the hippocampus, evoked by the sharp wave originating in CA3 (Fig. 1) [16]. It remains local between the CA3 pyramidal cells and the peri-somatic inhibitory neurons $[20,21]$. Its duration in rat is $\mathbf{3 0 - 1 5 0 ~} \mathrm{ms}$ and the amplitude does not exceed $2.5 \mathrm{mV}$. The spikes are smaller and shorter, and the coupled ripples are more synchronous in humans (Fig. 2). The big amount (50,000-150,000) of hippocampal neurons involved in SPW-R elicit long-term potentiation (LTP), which in turn changes the synaptic weights between the hippocampal neurons.

The elimination of SPW-Rs abrogates memory consolidation $[22,23]$. Animal studies show that the cellular spike sequences in

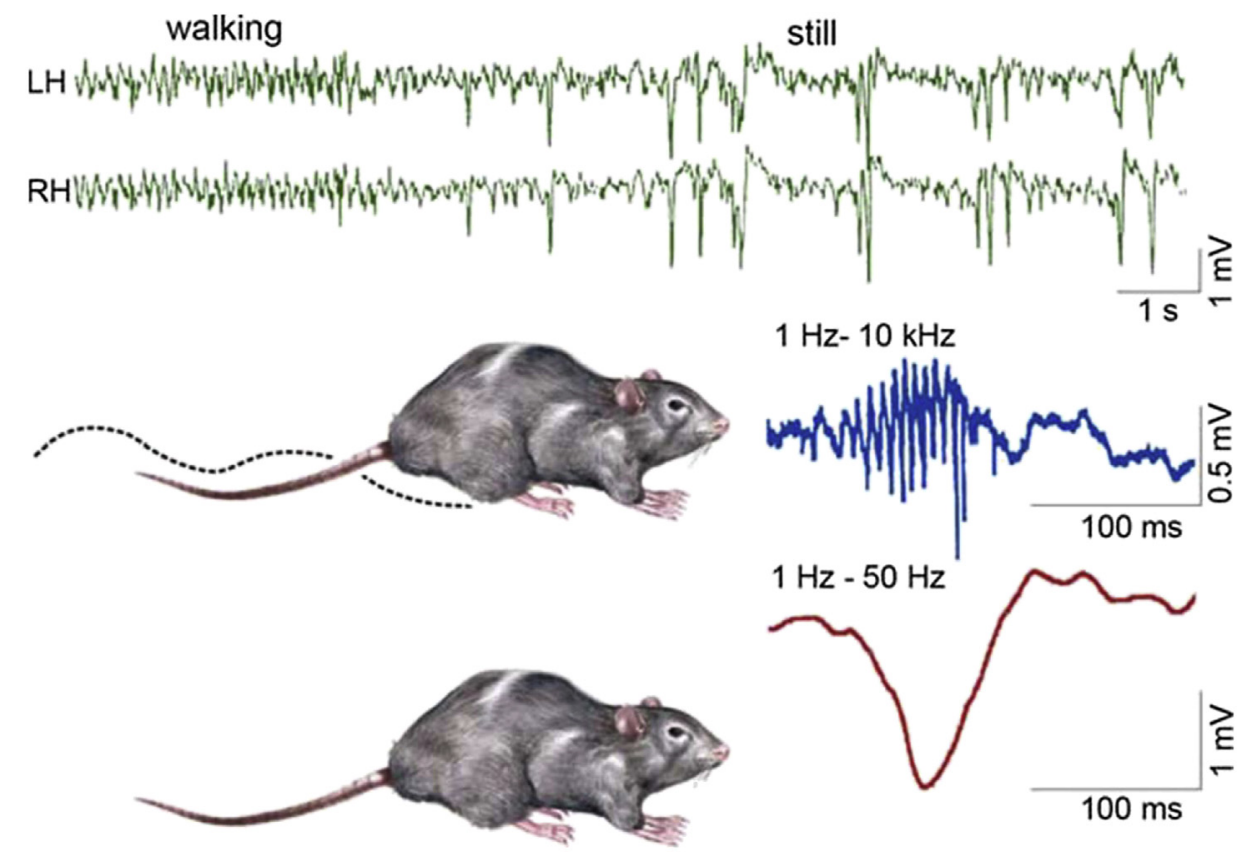

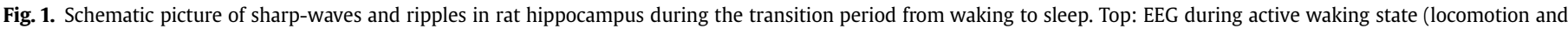

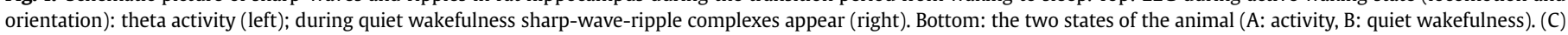
Enlarged picture of the sharp wave ripple complex: ripple (top) sharp wave (bottom) (After Buzsáki 2015). 


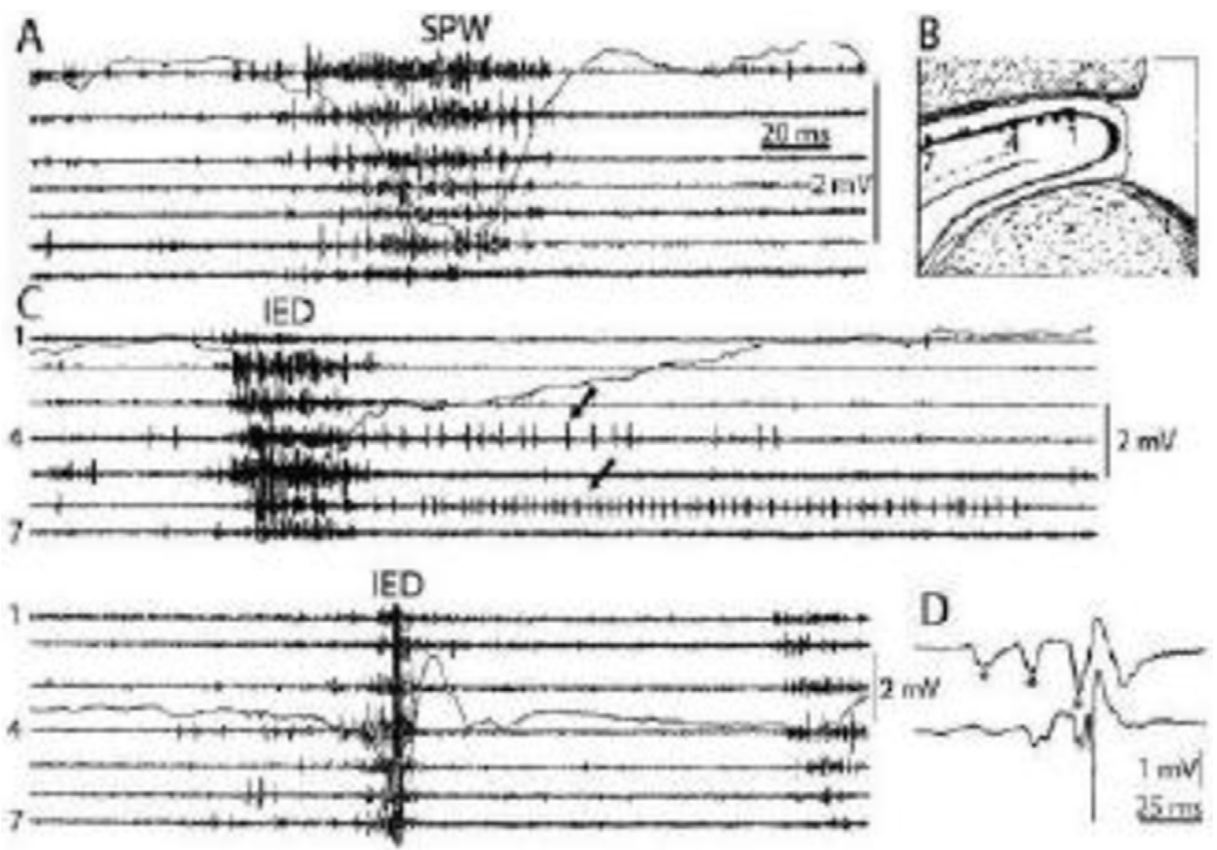

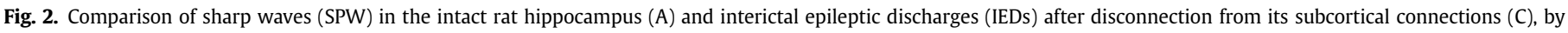

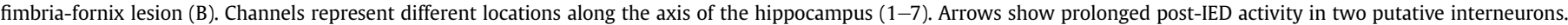

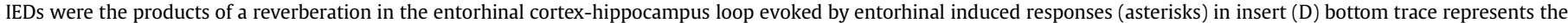

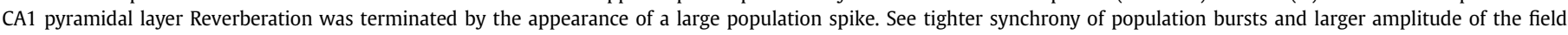
responses during IEDs. (After Buzsáki 2015 and 1991).

slow wave sleep are identical with the sequence found during SPWRs only faster and compressed [24-26]; the increase of the number of SPW-Rs after learning supports a similar scenario in humans $[27,28]$.

\section{The change of the hippocampo-neocortical memory process in MTLE}

SPW-Rs fringe on the edge of a shift to epileptic excitation, giving a hint, why the hippocampus is the most epilepsy-prone structure of the brain. SPW-R is the normal counterpart of the epileptic twin, spike-fast ripple [15]. Ripples above $250 \mathrm{~Hz}$ are essential markers of epilepsy [29]. Also the epileptic spike is similar to SPW-R sharp waves just shorter, smaller and linking with high frequency oscillations (HFO) (fast ripples) (Fig. 2). This similarity of the physiological and pathological variants highlights the vicinity of epilepsy to normal functioning. Stimulating the ventral commissure, Shatskikh et al. [6] elicited large population spikes in the CA1 region of the hippocampal pyramidal neurons. The elicited spikes were similar to the spontaneous ones. The stimulated animals developed serious memory loss. Clemens et al. and Kleen et al. [7,8] evidenced the link between memory disturbances and hippocampal sleep spiking in human MTLE patients. Frauscher et al. [30] studied hippocampal sleep spindling in human MTLE with implanted deep electrodes. Because hippocampal spindling and the increase of spiking correlated negatively, they assumed that spindles transformed to spikes; similarly to the proposed transformation of spindling to bilateral SW activity in absence epilepsy. Recently Gelinas et al. using a rat kindling model, provided elegant experimental evidence for SPW-R's conversion to epileptic variants as well as for IEDs' interference with temporo-frontal memory consolidation. They have shown that the hippocampus displaying sleep related IEDs cannot process normal engrams [31,32].
In summary, the progressive transformation of SPW-Rs to spikes and fast ripples may be dynamic functional factors obstructing memory consolidation.

Fig. 3 illustrates the abundant flow of discharges recorded in bilateral foramen ovale electrodes during sleep in one of our patients under pre-surgical evaluation.

These results support that beyond structural hippocampal sclerosis, IEDs might contribute to the memory loss of MTLE patients by at least two mechanisms:

1) Daytime spikes obstruct the elaboration of normal engrams (a hypothesis).

2) Sleep-related epileptic discharges as dysfunctional dummies of SPW-Rs are unable to process and consolidate engrams [31,32].

Clinical data support that ictal and interictal epileptic activity cause memory loss.

Since the famous H.M case, undergoing bilateral hippocampectomy, the essential role of the paired hippocampi in human declarative memory has become obvious [33]. Due to the spread of surgical neuropsychology testing of TLE patients as well as to the progress of the neuro-imaging the learning of memory-production has improved. However, we do not see the entire mechanism and the whole harm caused by epilepsy. The scanty neuropsychological capacity mainly applied in surgical cases and, the lack of long-term follow-up studies limits our knowledge. Analyzing the structural damage of the hippocampus in line with hippocampal discharges would be especially useful.

Several ictal semiology phenomena reflect memory changes (e.g., déjà-vu and jamais-vu auras, pure amnestic fits etc.). One may wonder whether an abrupt drop of memory rather than a global disturbance of consciousness underlies patients' loss of contact in their complex partial seizures. 


\section{Bilateral temporal lobe epilepsy : scalp and bilateral foramen ovale records during NREM}

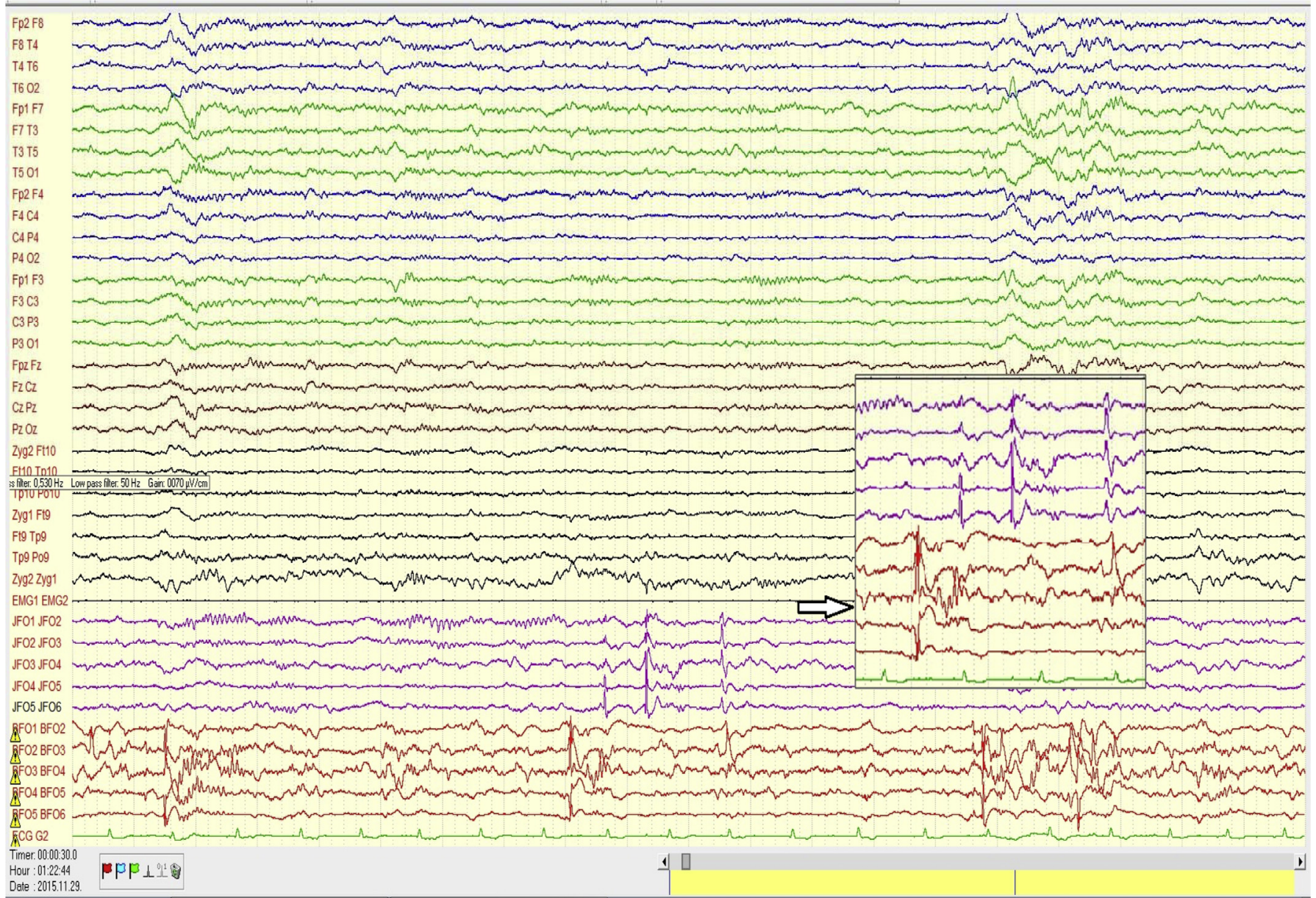

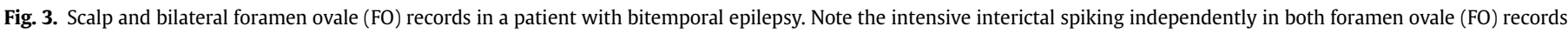

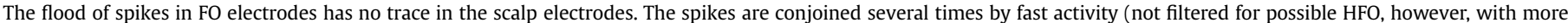
appropriate filtering, HFO could be made visible).

\section{The perisylvian cognitive network (PN) and idiopathic age- dependent focal/regional childhood epilepsies (IFCE). The malignant transformation to electrical status epilepticus in sleep (ESES) and Landau-Kleffner syndrome (LKS)}

The PN is a large scale cognitive brain system of human communication e.g., speech, reading/writing and working memory, closely interconnected with the thalamus. Due to its delicate functions it is highly vulnerable to developmental errors.

IFCE as RE and PS are transient developmental conditions typically starting in schoolchildren and ending in puberty. This group constitutes the most prevalent type of epilepsy in childhood.

\section{Rolandic epilepsy (age-dependent childhood epilepsy with centro-temporal spikes)}

RE affects mentally normal children in the age group 2 to 13 . The rare $(1-2 / y)$ seizures evolve during NREM sleep around sleep onset. Attacks strictly related to sleep occur in two third of patients. The original definition has excluded any lesional background; however, it may affect children with brain damages as well. In a study of non-lesional cases, neuroimaging revealed a thinner cortex in RE patients compared to controls in the frontal, temporal and, occipital regions [34], supporting a neurodevelopmental origin.

The EEG hallmark of the syndrome is the interictal CTS (Fig. 4a). It is a high voltage sharp wave closed by a slow wave in the midtemporal region occurring in clusters or runs in a bilateral independent pattern in half of cases. The centrotemporal potential-field may shift to the frontal or parietal regions with unchanged seizure semiology. Typically, it is a fronto-temporal dipole, localized perpendicularly to the axis of the Sylvian fissure (Fig. 4b). Mapping studies in RE and PS patients [34-37] found the dipole of CTS around the big cortical sulci (Sylvian fissure, parieto-occipital sulcus and calcarine fissure in PS). CTSs are associated with 93.8-152.3 Hz ripples in RE [38] especially near seizures. In atypical cases turning to ESES, proportionately to the poor prognosis, the ripples had higher voltage.

Slow wave sleep is the main enhancer of seizures and IEDs. Clemens and Majoros [75] found the strongest activation during deep slow wave sleep, especially on the descending slopes of the first sleep cycles. Beelke et al. and Nobili et al. [39,40] found a robust correlation of IEDs with spindling; unlike other groups of epilepsies where IEDs associate to the A1 phase of Cyclic Alternating Pattern (CAP).

About $1 / 4$ of patients have one or more family members presenting with seizures and the non-epileptic first degree relatives of $1 / 3$ of patients carry CTS. Also twin-studies have supported a genetic 
Genotype SRPX2, ELP4, GRIN2A (Rudolf et al 2009,

Lemke et al 2013, Lesca 2012)
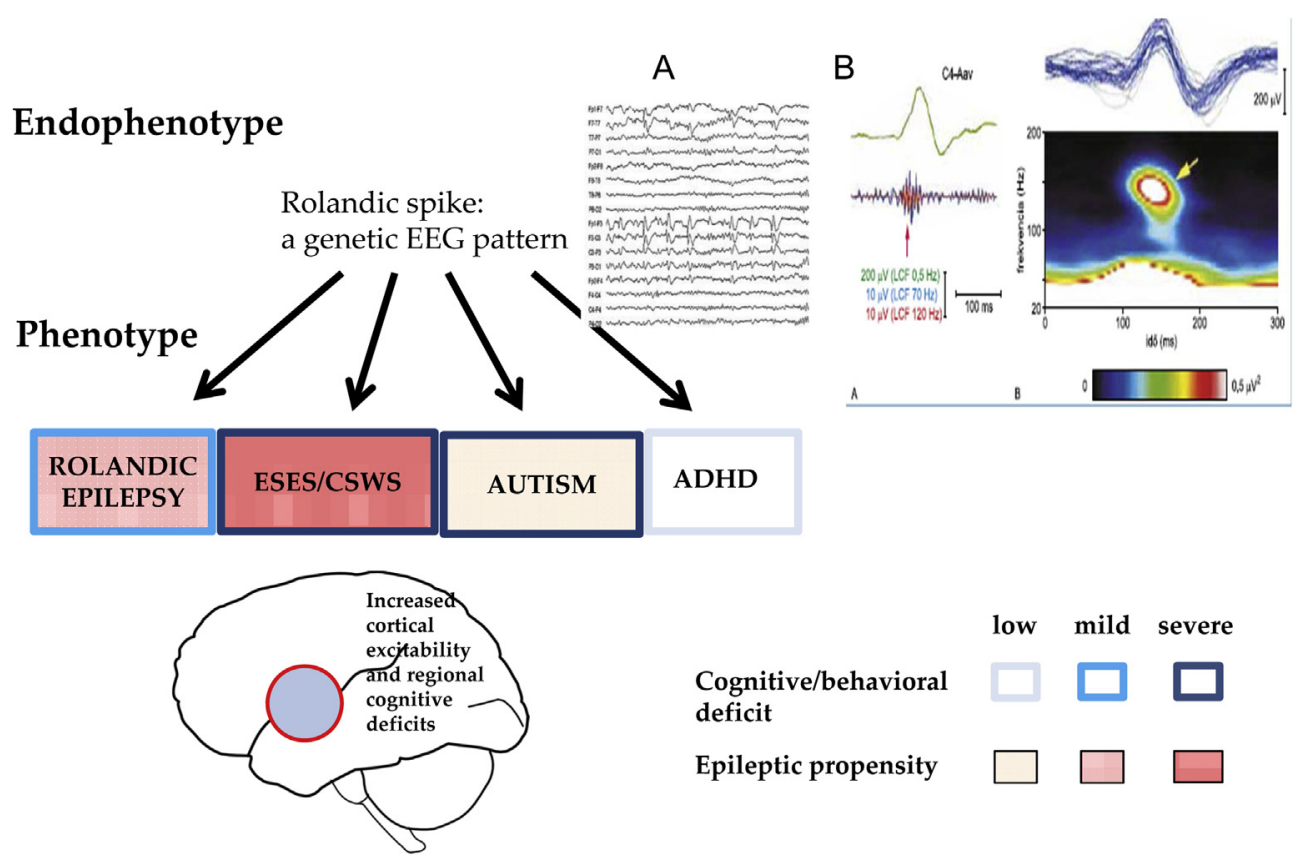

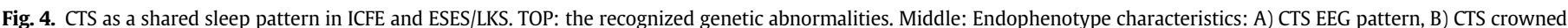

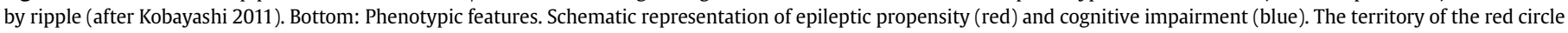

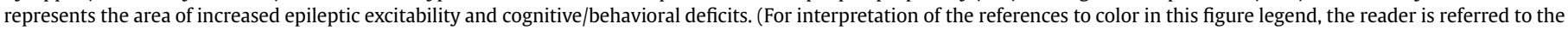
Web version of this article.)

background. Recent studies highlighted the possible role of the SRPXA, GRIN2A and ELP4 genes [41-45], involved in cortical development.

\section{Panayiotopoulos syndrome (PS)}

Describing it in 1999, Panayiotopoulos further explicated the syndrome in an additional paper [46,47]. A 2006 consensus report characterized it as "benign, age-related, focal type of epilepsy developing in early and mid-childhood [48]. The interictal EEG consists of multiple/ changing localization, most consequently occipital; morphologically BCTE-like discharges". PS is prevalent in children younger than 6 constituting $13 \%$ of all epilepsies. It may associate with RE.

In PS, mapping studies found potential fields around the occipito-medial and parieto-occipital regions as well as around the calcarine sulcus [36,37]. Seizures start in age 3 to 6 and cease around $14-15 \mathrm{y}$, occurring in sleep in $2 / 3$ of cases [49]. The electromorphologic features are similar to RE with variable localization and hemispheric distribution CTSs. NREM sleep has a less strong activating effect than in RE.

The seizures are not always stereotyped. Half of them last longer than $30 \mathrm{~min}$ and may aggregate to status epilepticus. Most seizures manifest with autonomic signs. Nausea, retch and vomiting are most frequent featuring most seizures. Color-changes, cyanosis, dilated pupils, temperature-swings, incontinence, salivation, vehement bowel movements and syncope may present as sole ictal phenomena or may be joined by convulsions or atony. Eye deviation as an initial symptom is less frequent than deemed earlier. The genetic background is unknown.

\section{The transition to ESES/LKS}

Since the seventies of the last century, several age-dependent childhood epilepsy patients with a malignant disease-turn appeared in the literature: the children became speech-loss or suffered from a global cognitive decline [48,49]. Their IEDs inundated the cortical convexities during all NREM sleep stages constituting electrical status epilepticus. This nearly continuous and widespread bilateral spiking during slow wave sleep may last for months or years without clinical seizures.

Tassinari et al. called this malignant variant "encephalopathy related to electric status epilepticus" [50-52] now known as electrical status epilepticus in sleep (ESES). Its treatment has remained unresolved, the antiepileptic drugs are ineffective [53]. ESES may start in early childhood and cease before puberty $[54,55]$. The severity and reversibility of cognitive loss correlates with the duration and recovery of ESES [56,57]. The degree and type of cognitive loss depend on the degree and localization of IEDs during NREM sleep [89]. A deviant RE course may underlie ESES [53-58].

Acquired epileptic aphasia named Landau-Kleffner syndrome (LKS) honoring the first descriptors, is a regional variant of ESES, it is another malignant variant of PN conditions. The abundant spikes of LKS cluster in the posterior temporal region of the dominant hemisphere [59], with no underlying lesion. The affected children lose speech-perception after normal speech had evolved prior to the disorder $[50,53,60]$.

Genetic findings support the notion of disease spectrum involving RE, PS, atypical RE, LKS and ESES [41,42].

We published an extensive conception called "The perisylvian epileptic network" on the spectrum of benign focal childhood epilepsies transforming to LKS or ESES [60]. In line with us, Fejerman [61] has analyzed the features of the malignant diseasecourse named by him "atypical Rolandic epilepsy". Di Negri published a very similar unifying concept highlighting the spectrum-like nature of IFCE ranging from RE and PS to ESES and LKS [63]. 


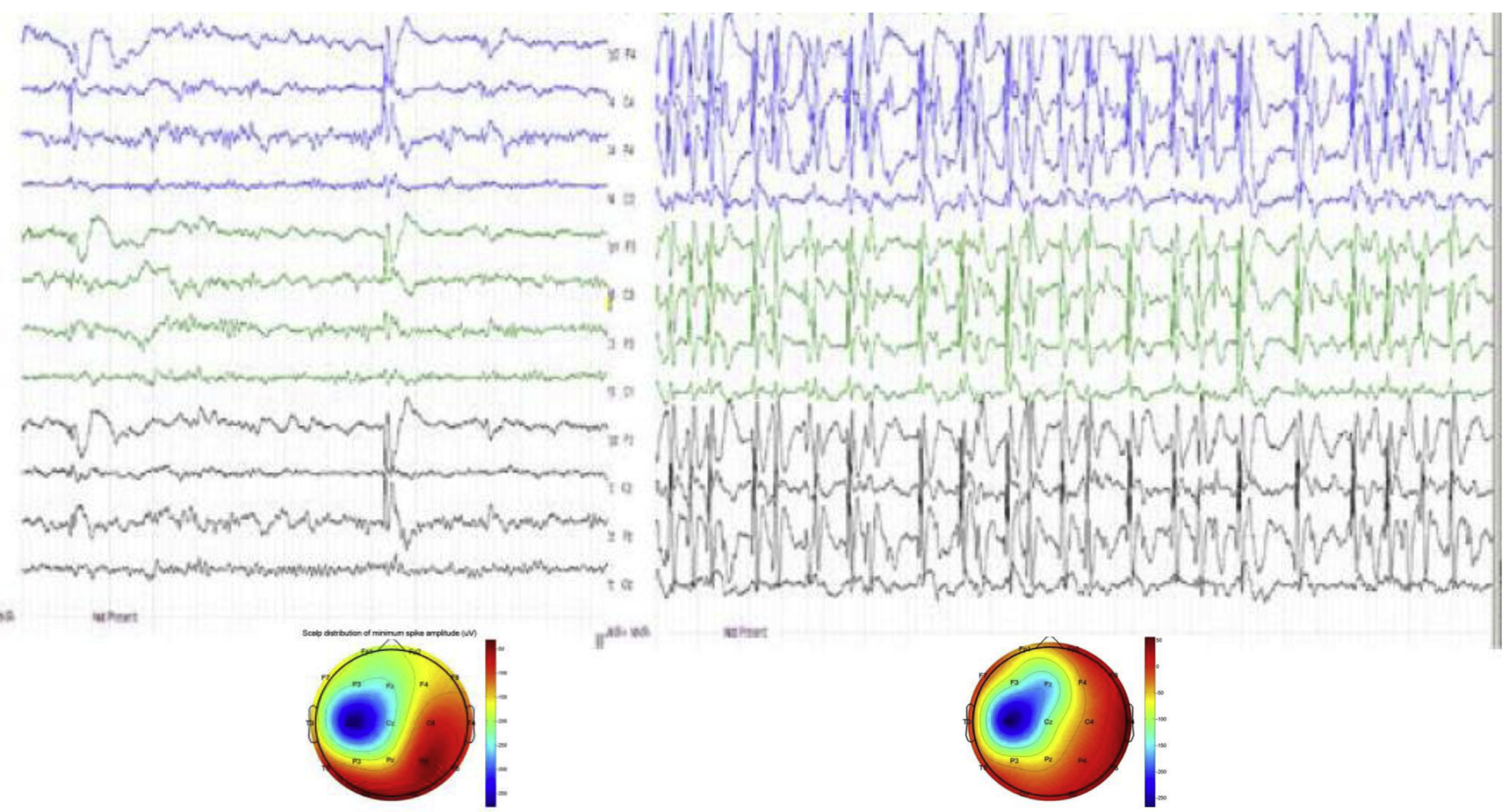

Fig. 5. Transition from wake state (left) to NREM sleep (right) shows the appearance of abundant spiking (ESES) in an 8 y-old boy. Bottom: amplitude mapping: averages of 10 awake (left) and 100 sleep (right) spikes. Note the similar spatial and laterality patterns of the focal spike fields in wakefulness and sleeping. 


\section{The continuity of IEDs in perisylvian spectrum-disorders}

The critical sleep-enhancement of CTS is a fundamental feature of the whole spectrum [64]. There is a continuity in the amount, synchronization, and bilateralisation of spikes [61] and fast ripples from the benign conditions (IFCE) to the malignant encephalopathic variants $[38,89]$.

CTS have a stepwise evolution. If it presents without ripples, there is no clinical epilepsy. Ripples join CTS in the RE-PS phenotype (Fig. 4a and b) and in malignant cases developing to ESES/LKS abundant spikes and ripples occur (Fig. 8) [38].

Endophenotypes are shared modules of phenotypically different complex disorders e.g., in schizophrenia and in certain epilepsies. CTS is an endophenotype shared by RE, PS, ESES/LKS. It is more prevalent in the sleep of autism spectrum disorder $[63,64]$ and ADHD [66,67] patients than in the normal population (Fig. 4.). Tittering upon the edge of non-epilepsy and epilepsy, it has a vague nature. Non-epileptic CTS present without ripples in autism [64,65] and ADHD [66,67]. It behaves as an augmented evoked potential responding to acoustic and tactile stimuli $[68,69]$ in certain infants, while epileptic CTS in RE are joined by fast ripples HFO $[38,63,70]$.

Recently Mirandola et al. [71] published a case report on a thirteen year-old boy presenting with moderate learning difficulties affecting reading, writing and calculation. He had no clinical epilepsy but right dominant bilateral independent CTS with important enhancement during NREM sleep, not reaching the $85 \%$ cut-off for ESES. FMRI In wakefulness revealed a right dominant increment of the BOLD signal in the sensory-motor cortex, while during NREM sleep, it discovered a widespread CTS-related cortical-subcortical network over the thalamic-perisylvian region.
This case shows that CTS during NREM sleep may link with a large pathological network with no epilepsy and it carries a risk of cognitive decline.

Thus, CTS might be the EEG sign of local cortical developmental delay and increased local excitability $[46,72,73]$ with a potential to regress or progress to epilepsy and its malignant variants.

\section{The continuity of sleep enhancement in PN spectrum disorders}

In cases where RE and PS patients had had sleep recordings prior to their progression to ESES; their IEDs were similar to those later seen in ESES; just quantitative differences occurred. This supports a continuity in the degree of sleep activation as well. In addition, the abundant discharges of ESES in sleep versus CTS in waking constitute similar potential-fields (Fig. 5.). While the activation rate of CTS without ripples during sleep is unknown, CTS with ripples strongly activate during sleep in RE patients [72-74]. The earlier rigorous $85 \%$ covering of NREM sleep by IEDs as the criterion for diagnosing ESES has become more flexible recently; an important continuous regional, hemispheric or global activation of IEDS is accepted. Thus, the view on ESES as a unique entity has turned to a spectral range concept. There are continual features in time and territory of sleep activation, during the evolution and remission of ESES, too [75] (Fig. 6).

There is another important feature differentiating PN spectrum conditions (IFCE) from the rest of sleep-related epilepsies. In PN conditions, CTS couple with sleep spindling [76,77,39,40] (Fig. 7) unlike in other epilepsies where spikes link with CAP A1 phase slow waves [78].

\section{A) Left dominant bilateral temporo-central monofield}

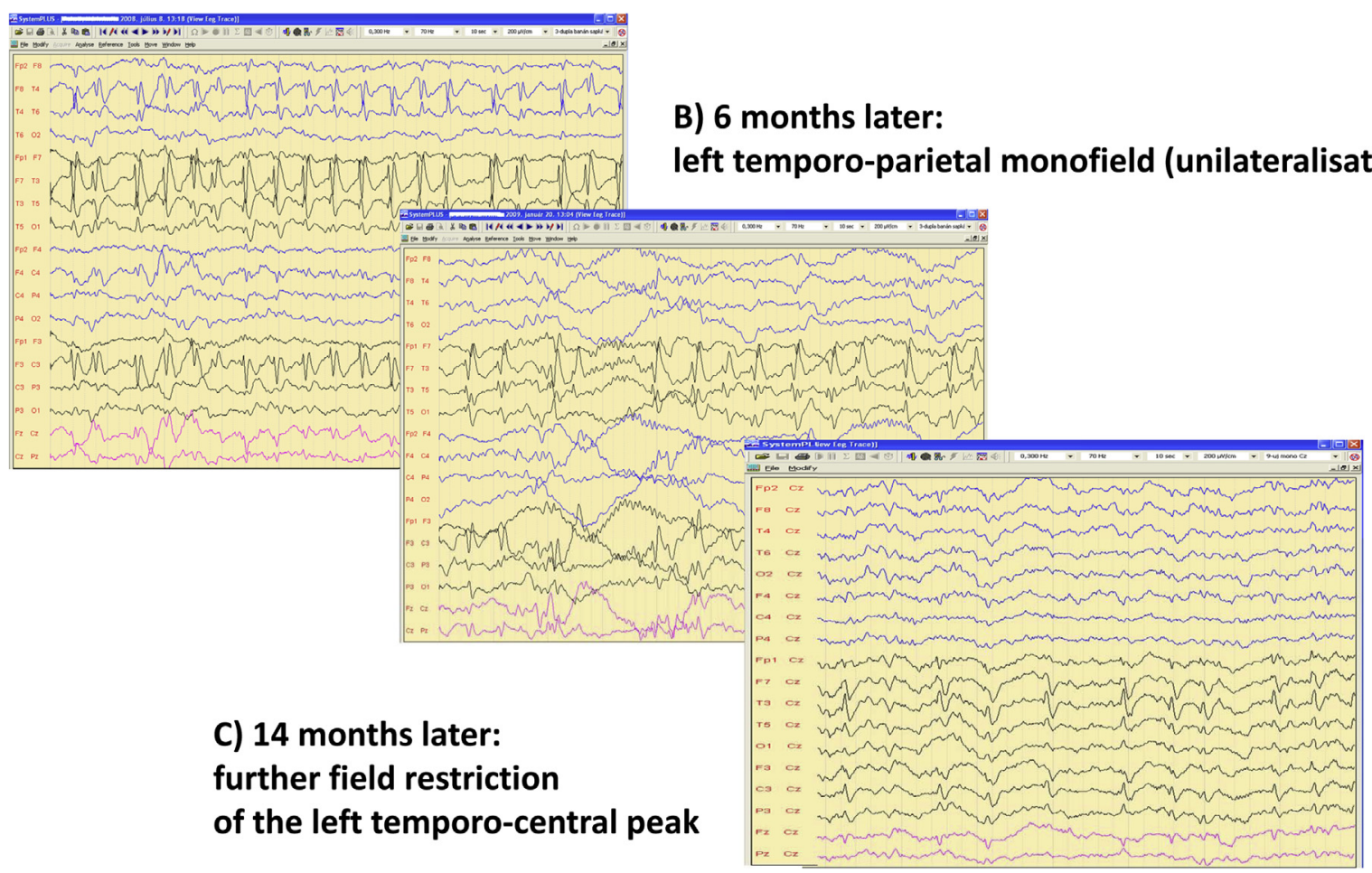

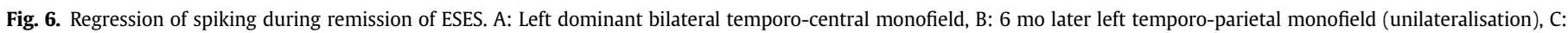
14 mo later: more field restriction of the left temporo-central peak. 


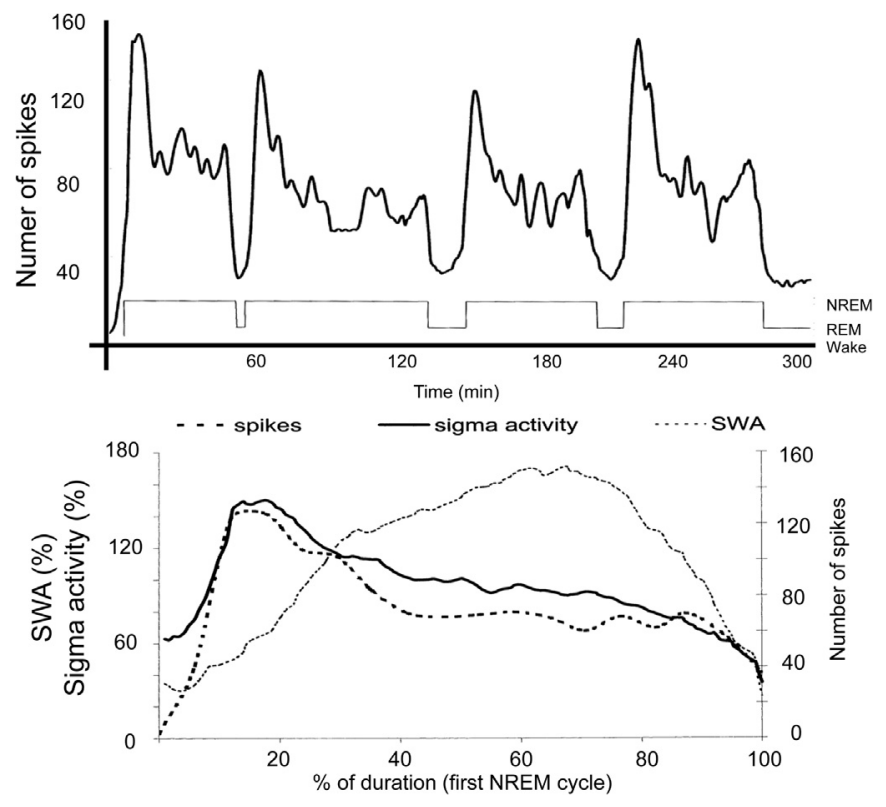

Fig. 7. The relationship between sleep oscillations and the occurrence rate of CTS among the spectrum of perisylvian epileptic network disorders. Top: Distribution of CTS across the sleep cycle. Bottom: Distribution of IEDs (green dashed line); the EEG sigma band (blue line $=12-16 \mathrm{~Hz}$ ) and slow wave activity red line $=0.5-4.0 \mathrm{~Hz}$ ) across the first NREM cycle. It is clearly seen that CTS goes parallel with sigma frequencies (sleep spindles), and not with sleep slow wave activity. (After Nobili et al. (2011).

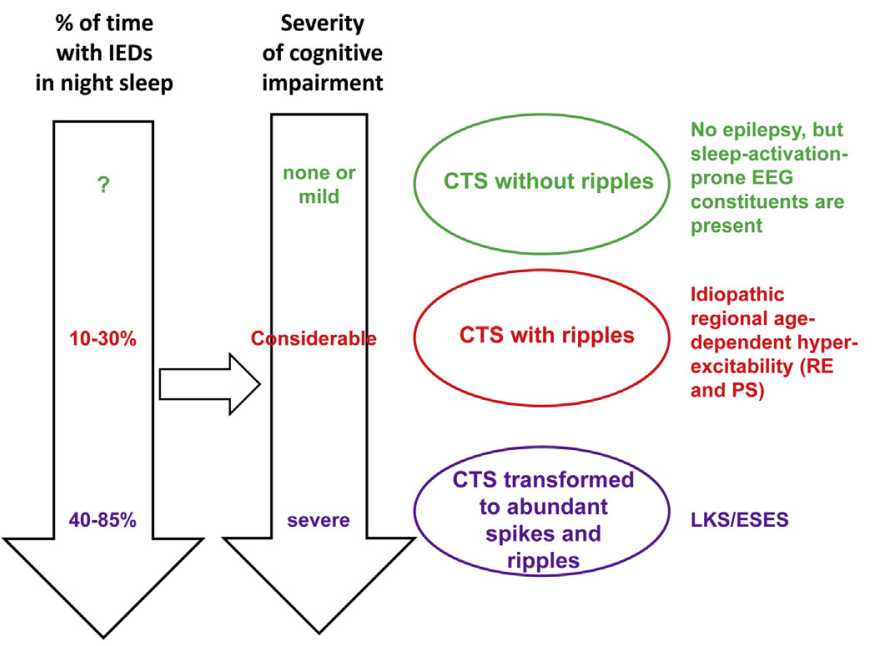

Fig. 8. Spectrum disorders of the perisylvian epileptic network. Continuity in the constituents across disorders (syndromes) is shown. Right: the centro-temporal spike (CTS) which is the basic endophenotype of the spectrum. The three levels of CTS characteristics in clinical syndromes: green $=$ CTS without ripples corresponds to lack of epileptic seizures; red = CTS with ripples corresponds to idiopathic regional age dependent hyper-excitability (Rolandic epilepsy and Panayiotopoulos syndrome); purple $=$ abundance of CTS-like discharges in sleep with ripples corresponds to ESES/ LKS. Left: The perpendicular arrows represent the increasing amount of epileptic activity in sleep and increasing degree of cognitive impairment. The horizontal black arrow represents the assumed causal relationship between sleep epileptic activity and cognitive impairment. IEDs: interictal epileptic discharges. (For interpretation of the references to color in this figure legend, the reader is referred to the Web version of this article.)

\section{The continuity of cognitive impairment in PN conditions}

In contrast with the early expectation on a benign outcome of IFCE, several recent publications revealed a wide range of associated cognitive and behavioral disturbances. A systematic review and meta-analysis of 42 case-control samples comprising 1237 untreated RE children and 1137 healthy controls showed significantly lower scores in eight cognitive domains, most importantly in long term storage and retrieval [79]. Other studies found cognitive impairment phenotypes affecting language and academic performance [80]. Bilateral discharges associated to more severe cognitive impairment [81,82].

The cognitive changes found in RE and PS fill the gap between them and their atypical variants progressing to ESES and LKS. A recent conference on idiopathic focal epilepsies "The lost tribe state of the art" [83] supports this approach in a multilateral way.

\section{Shared genetic background}

PN spectrum conditions share several genetic features. Recent research found the SRPX2 and ELP4 genes involved in epileptic sleep activation, possibly through influencing cell motility, migration and, adhesion [41]. Lemke et al. [45] revealed changes in the gene encoding the NMDA receptor NR2A subunit as a major genetic risk factor of PN spectrum-conditions. They found new heterozygous mutations in GRIN2A in 27 out of 359 affected individuals from two independent cohorts with growing frequency toward the ESES end.

In the RE-ESES/LKS spectrum, increased copy-number variations were found in the genomic architecture of several genes encoding cell adhesion proteins and there are some hints pointing the autism spectrum as well [42].

The continuity of PN spectrum conditions and the evolution of the syndrome constituents is summarized in Fig. 8.

\section{Other infantile and childhood encephalopathies}

Epileptic encephalopathies (EEs) (early infantile epileptic encephalopathies, West-syndrome, Lennox-Gastaut syndrome) constitute a contradictory however, widely used group in epileptology; recognized by the International League against Epilepsy. EEs are epilepsy-related conditions of early-affected large brain systems, likely involving the cortico-thalamic system. The main criterion is that the associated cognitive symptoms are due to epilepsy, encephalopathies caused by brain lesions and drugs are not included in this group. There is a conceptual difference between EEs and encephalopathies with epilepsy. In the latter group, a common etiology e.g., tuberous sclerosis underlies epilepsy and cognitive symptoms, while for example in ESES, sleep-related IEDs cause a cognitive loss.

The concept of system epilepsies overlaps with EEs [84,85]. For understanding the two steps in the evolution of EEs, the term "developmental epileptic encephalopathies" was proposed recently [86].

The weakness of the EEs category is that it might blur the actual mechanism of cognitive decline [87,88].

EEs typically start in infancy or early childhood. The specific combination of symptoms constituting different EEs might have a common pathomechanism caused by variable etiologies. Some EEs may have a genetic background. There is a progressive evolution to the full-blown picture in most cases; becoming stagnant and resistant to treatment after. In a sensitive early age, the epileptic disorder takes over the organization of physiological networks involved in plasticity e.g., in Lennox-Gastaut syndrome [89].

Childhood EEs share abundant IEDs during NREM sleep. The suppression burst activity; a sleep-variant of hypsarrhythmia covering the whole sleep in early neonatal encephalopathies likely interferes with normal brain development. It disfigures sleep in West syndrome. The frequent and variable topography seizures contribute to the cognitive harm caused by IEDs. The cognitive improvement experienced when Vigabatrin helps hypsarrhythmia and epileptic spasms, supports their causative role in cognitive loss. 
Table 1

The common features of epileptic encephalopathies.

- Most of them are age-related, starting in early childhood, in the period of high brain plasticity.

- Cognitive dysfunction is supposed to be underlain by the disordered association cortex.

- There is pathological HFO (fast ripples) during sleep in all forms.

- Interictal epileptic activity has a more important harm than seizures themselves.

- Epileptic encephalopathies constitute a spectrum of an age dependent syndrome chain (Ohtahara syndrome-West syndrome- Lennox-Gastaut syndrome).

- Because several epileptic encephalopathy patients have genetic, metabolic, hypoxic or other brain damages, it is hard to identify those cognitive deficits caused by epilepsy itself.

The diffuse slow SWs and generalized fast paroxysmal activity with or without tonic seizures in Lennox-Gastaut syndrome interfere with normal cognitive functioning as well.

Even scalp electrodes can detect now the abundant fast ripples during NREM sleep [90]. There are fast ripples in most childhood EEs, correlating with the severity and progression of EE [38,91] and offering another hint of their impact on cognitive impairment. Because the cut-off frequencies of fast ripples in infants and children are not yet clear, conclusions regarding the significance of different frequency-ranges should be taken cautiously.

In MTLE and PN spectrum conditions there are relevant studies supporting the interference of epileptic transformation with plastic sleep functions and cognition. There are much less data in EEs, but one may suspect similar mechanisms underlying the cognitive decline in EE patients.

We summarize the common features of childhood encephalopathies in Table 1.

\section{Discussion}

In this paper, we review three types of epilepsies disfiguring major brain systems by the derailment of NREM sleep circuits.

The first one is temporal lobe epilepsy where SPW-Rs involved in memory processing transform to spikes and pathological HFO (fast ripples) compromising the declarative memory system.

The second example is the group of IFCE progressing to ESES/ LKS characterized by severe cognitive decline.

The third one is the group of EEs, where the abundant spiking and HFO (mainly inNREM sleep) interfere with sleep plastic functions.

In our recent book [62] we have reviewed these transformations more comprehensively. We suggested a common way how certain major epilepsies compromise sleep plastic functions causing cognitive impairment. This key mechanism is the consequence of the plasticity-dependent strong bond between NREM sleep and epilepsy and provides an angle for learning developmental epilepsies.

We are on the way to see why the cognitive decline in epilepsies associates mainly with IEDs of NREM sleep [9-13] in accordance with the synaptic homeostasis theory [92].

Sleep-related memory consolidation makes slow wave sleep the pledge of learning, justifying the need and seemingly uneconomical presence and persistence of sleep across the phylogeny. IEDs interweaving NREM sleep may interfere with its plastic functions; vividly depicted by Tassinari in the description of "Penelope syndrome" ${ }^{1}$ [93].

A vicious circle can be delineated in the sleep-epilepsy-cognition triangle: slow wave sleep is distorted by IEDs compromising normal sleep functions. Thus the cognitive harm is not the direct consequence of epilepsy, rather its indirect complication through the

\footnotetext{
1 In the legendary epos of Homer "The Trojan war" during the absence of Odysseus, Penelope his wife told to her proposers that she needed to weave her father-in-law's Laertes funeral shroud first, she could choose from among them only after. What she weaved during the day, she unraveled secretly during each night, delaying the time of decision (Analogy: what is built up in the neuronal networks during the day cannot be utilized due to an interference by night-time spiking).
}

interference with sleep plasticity. This important cascade of events is increasingly recognized providing an explanation of cognitive decline in EEs, in addition to lesional and pharmacological factors.

Recent studies on the sleep of ESES patients indirectly suggest the deficit of night-time synaptic down-scaling [9,10,12,92]. Recently Bölsterli et al. [10] have shown that after the recovery from ESES the night-time decline of slow waves restored, and the outcome was better if sleep slow wave decline had remained somewhat preserved during the active ESES period.

There seem to be two different ways of memory-harm caused by IEDs. In the one, spikes interfere with memory consolidation during NREM sleep e.g., in MTLE. In the second one, IEDs interfere with the general synaptic down-scaling process during NREM sleep e.g., in ESES and LKS.

Recent research links epilepsy to network activities; considering interictal and ictal signs as network states. Ictal states represent pathological peaks of activity, expressed by episodic changes of behavior; interictal states constitute a more continuous background of the disorder.

The influence of this hidden continuous and insidious activity manifesting no spectacular events has remained more or less unknown even after many years of intensive epilepsy research. We certainly need a switch from dealing with transient to long-term (and possibly progressive) cognitive impairment. Performing repeated sleep studies combined with cognitive follow up studies is hard; requiring highly organized cooperative multi-center work embracing decades, and this is before us.

In this paper we used the system-epilepsy approach to demonstrate how sleep plastic functions are compromised by the epileptic derailment occupying (,hijacking” [94]) them. The concept of system-epilepsy $[84,85]$ comes from the now generally accepted notion of epilepsy as a neuronal network disease. Most neural networks serve certain physiological systems. Major epilepsies can be conceived as physiological systems in which an epileptic over-excitation (derailment) exaggerates the functions when they are activated. Sensory or praxis induced reflex epilepsies may be reinterpreted so [Szücs et al. submitted], and certain nonsensory systems like sleep, arousal or the memory system might be additional examples [95].

One of the advantages of the system epilepsy approach is, that it may highlight the interictal symptoms of epilepsy as memory disturbances and other cognitive deficits. The ictal signs are more emphasized nowadays (mainly due to the highly developing epilepsy surgery) while interictal ones remain in shadow compared to their significance.

\section{Practice points}

- Due to the link of epilepsy and NREM sleep, sleep EEG is indispensable in the evaluation of epilepsies.

- Sleep-relatedness and interictal epileptic activity have major role in chronic cognitive harm.

- Sleep EEG may clarify the cause of unexplained childhood cognitive decline or dysphasia. 


\section{Research agenda}

- Assessing the share of spiking and structural hippocampal damage in the cognitive loss of MTLE.

- Cognitive impairment needs to be correlated with the enhancement of sleep spiking in conditions with cognitive decline.

- There is pressing need to find pharmaco-therapy treatment against interictal epileptic activity.

\section{Conflicts of interest}

The authors have no conflict of interest to declare.

\section{Acknowledgement}

The authors are grateful for the support of the National Brain Research Program, Hungary 2017-1.2.1-NKP-2017-00002.

\section{Appendix A. Supplementary data}

Supplementary data to this article can be found online at https://doi.org/10.1016/j.smrv.2019.01.003.

\section{References}

[1] Zhao F, Kang H, You L, Rastogi P, Venkatesh D, Chandra M. Neuropsychological deficits in temporal lobe epilepsy: a comprehensive review. Ann Indian Acad Neurol 2014;17:374-82.

[2] Holmes GL. What is more harmful, seizures or epileptic EEG abnormalities? Is there any clinical data? Epileptic Disord 2014;1:S12-22. Spec No.

[3] Binnie CD. Significance and management of transitory cognitive impairment due to subclinical EEG discharges in children. Brain Dev 1993;15:23-30.

[4] Binnie CD. Cognitive effects of subclinical EEG discharges. Neurophysiol Clin 1996;26:138-42.

[5] Halász P. The relationship of medial temporal lobe epilepsy with the declarative memory system. J Epileptol 2016;24:157-65.

[6] Shatskikh TN, Rag havendra M, Zhao Q, Cui Z, Holmes GL. Electrical induction of spikes in the hippocampus impairs recognition capacity and spatial memory in rats. Epilepsy Behav 2006;9:549-56.

[7] Clemens Z, Mölle M, Erőss L, Barsi P, Halász P, Born J. Temporal coupling of parahippocampal ripples, sleep spindles and slow oscillations in humans. Brain 2007;130(Pt 11):2868-78.

[8] Kleen JK, Scott RC, Holmes GL, Roberts DW, Rundle MM, Testorf M, et al. Hippocampal interictal epileptiform activity disrupts cognition in humans. Neurology 2013;81:18-24.

[9] Bölsterli BK, Schmitt B, Bast T, Critelli H, Heinzle J, Jenni OG, et al. Impaired slow wave sleep downscaling in encephalopathy with status epilepticus during sleep (ESES). Clin Neurophysiol 2011;9:1779-87.

[10] Bölsterli BK, Gardella E, Pavlidis E, Wehrle FM, Tassinari CA, Huber R, et al. Remission of encephalopathy with status epilepticus (ESES) during sleep renormalizes regulation of slow wave sleep. Epilepsia 2017;58:1892-901.

[11] Bölsterli BK, Fattinger S, Kurth S, LeBourgeois MK, Ringli M, Bast T, et al. Spike wave location and density disturb sleep slow waves in patients with CSWS (continuous spike waves during sleep). Epilepsia 2014;55:584-91.

[12] Cantalupo G, Rubboli G, Tassinari CA. Night-time unravelling of the brain web: impaired synaptic downscaling in ESES-the Penelope syndrome. Clin Neurophysiol 2011;122:1691-2.

[13] Rasch B, Born J. About sleep's role in memory. Physiol Rev 2013;93:681-766

[14] García-Peñas JJ. Interictal epileptiform discharges and cognitive impairment in children. Rev Neurol 2011;52(Suppl. 1):S43-52.

*[15] Buzsáki G. Hippocampal sharp wave-ripple: a cognitive biomarker for episodic memory and planning. Hippocampus 2015;25:1073-188.

[16] Buzsáki G. Hippocampal sharp waves their origin and significance. Brain Res 1986;398:242-52.

[17] Buzsáki G. Two-stage model of memory trace formation: a role for "noisy" brain states. Neuroscience 1989;31:551-70.

[18] Chrobak JJ, Buzsáki G. Operational dynamics in the hippocampal-entorhinal axis. Neurosci Biobehav Rev 1998;22:303-10.

\footnotetext{
* The most important references are denoted by an asterisk.
}

[19] Csicsvári J, Hirase H, Czurkó A, Mamiya A, Buzsáki G. Oscillatory coupling of hippocampal pyramidal cells and interneurons in the behaving rat. J Neurosci 1999;19:274-87.

[20] Schlingloff D, Káli S, Freund TF, Hájos N, Gulyás AI. Mechanisms of sharp wave initiation and ripple generation. J Neurosci 2014;20:11385-98.

[21] Gulyás AI, Freund TT. Generation of physiological and pathological high frequency oscillations: the role of perisomatic inhibition in sharp-wave ripple and interictal spike generation. Curr Opin Neurobiol 2015;31:26-32.

[22] Girardeau G, Benchenane K, Wiener SI, Buzsáki G, Zugaro MB. Selective suppression of hippocampal ripples impairs spatial memory. Nat Neurosci $2009 ; 12: 1222-3$

[23] Roux L, Hu B, Eichler R, Stark E, Buzsáki G. Sharp wave ripples during learning stabilize the hippocampal map. Nat Neurosci 2017;20(6):845-53.

[24] Nádasdy Z. Spike sequences and their consequences. J Physiol Paris 2000;94: 505-24.

[25] Foster DJ, Wilson MA. Reverse replay of behavioural sequences in hippocampal place cells during the awake state. Nature 2006;440:680-3.

[26] Ji D, Wilson MA. Coordinated memory replay in the visual cortex and hippocampus during sleep. Nat Neurosci 2007;10(1):100-7.

[27] Cheng S, Frank LM. New experiences enhance coordinated neural activity in the hippocampus. Neuron 2008;7:303-13.

[28] O'Neil J, Senior TJ, Allen K, Huxter JR, Csicsvári J. Reactivation of experiencedependent cell assembly patterns in the hippocampus. Nat Neurosci 2008;11:209-15.

*[29] Frauscher B, von Ellenrieder N, Ferrari-Marinho T, Avoli M, Dubeau F, Gotman J. Facilitation of epileptic activity during sleep is mediated by high amplitude slow waves. Brain 2015a;138(Pt 6):1629-41.

[30] Frauscher B, Bernasconi N, Caldairou B, von Ellenrieder N, Bernasconi A Gotman J, et al. Interictal hippocampal spiking influences the occurrence of hippocampal sleep spindles. Sleep 2015b;38:1927-33.

*[31] Gelinas JN, Khodagholy D, Thesen T, Devinsky O, Buzsáki G. Interictal epileptiform discharges induce hippocampal-cortical coupling in temporal lobe epilepsy. Nat Med 2016;22:641-8.

[32] Boly M, Jones B, Findlay G, Plumley E, Mensen A, Hermann B, et al. Altered sleep homeostasis correlates with cognitive impairment in patients with focal epilepsy. Brain 2017;140:1026-40.

[33] Milner B. The medial temporal-lobe amnesic syndrome. Psychiatr Clin 2005;28:599-611.

[34] Vannest J, Tenney JR, Gelineau-Morel R, Maloney T, Glauser TA. Cognitive and behavioral outcomes in benign childhood epilepsy with centrotemporal spikes. Epilepsy Behav 2015;45:85-91.

[35] Wong PK. Source modelling of the Rolandic focus. Brain Topogr 1991;4: 105-12. Winter.

[36] Kanazawa O, Tohyama J, Akasaka N, Kamimura T. A magnetoencephalographic study of patients with Panayiotopoulos syndrome. Epilepsia 2005;46:1106-13.

[37] Yoshinaga H, Koutroumanidis M, Kobayashi K, Shirasawa A, Kikumoto K, Inoue T, et al. EEG dipole characteristics in Panayiotopoulos syndrome. Epilepsia 2006;47:781-7.

*[38] Kobayashi K, Yoshinaga H, Toda Y, Inoue T, Oka M. High-frequency oscillations in idiopathic partial epilepsy of childhood. Epilepsia 2011;52(10): 1812-9.

[39] Beelke M, Nobili L, Baglietto MG, De Carli F, Robert A, De Negri E, et al Relationship of sigma activity to sleep interictal epileptic discharges: a study in children affected by benign epilepsy with occipital paroxysms. Epilepsy Res 2000;40:179-86.

[40] Nobili L, Baglietto MG, Beelke M, De Carli F, De Negri E, Gaggero R, et al Distribution of epileptiform discharges during nREM sleep in the CSWSS syndrome: relationship with sigma and delta activities. Epilepsy Res 2001;44:119-28.

[41] Rudolf G, Valenti MP, Hirsch E, Szepetowski P. From rolandic epilepsy to continuous spike- and-waves during sleep and Landau-Kleffner syndromes: insights into possible genetic actors. Epilepsia 2009;50(suppl. 7):25-8.

[42] Lesca G, Rudolf G, Bruneau N, Lozovaya N, Labalme A, Boutry-Kryza N, et al GRIN2A mutations in acquired epileptic aphasia and related childhood focal epilepsies and encephalopathies with speech and language dysfunction. Nat Genet 2013;45(9):1061-6.

[43] Reutlinger C, Helbig I, Gawelczyk B, Subero JI, Tönnies H, Muhle H, et al Deletions in 16p13 including GRIN2A in patients with intellectual disability various dysmorphic features, and seizure disorders of the rolandic region. Epilepsia 2010;1:1870-3.

[44] Dimassi S, Labalme A, Lesca G, Rudolf G, Bruneau N, Hirsch E, et al. A subset of genomic alterations detected in Rolandic epilepsies contains candidate or known epilepsy genes including GRIN2A and PRRT2. Epilepsia 2014;55: 370-8.

[45] Lemke JR, Lal D, Reinthaler EM, Steiner I, Nothnagel M, Alber M, et al. Mutations in GRIN2A cause idiopathic focal epilepsy with Rolandic spikes. Nat Genet 2013;45:1067-72.

[46] Panayiotopoulos CP. Early-onset benign childhood occipital seizure susceptibility syndrome: a syndrome to recognize. Epilepsia 1999;40:621-30.

[47] Panayiotopoulos CP, editor. Panayiotopoulos syndrome: a common and benign childhood epileptic syndrome. London: John Libbey, Eastleigh; 2002.

[48] Ferrie C, Caraballo R, Covanis A, Demirbilek V, Dervent A, Kivity S, et al Panayiotopoulos syndrome: a consensus view. Dev Med Child Neurol 2006;48:236-40. 
[49] Caraballo R, Cersósimo R, Fejerman N. Panayiotopoulos syndrome: a prospective study of 192 patients. Epilepsia 2007;48:1054-61.

[50] Patry G, Lyagoubi S, Tassinari CA. Subclinical electrical status epilepticus induced by sleep in children. Arch Neurol 1971;24:242-52.

*[51] Tassinari CA, Rubboli G, Volpi L, Meletti S, d'Orsi G, Franca M, et al. Encephalopathy with electrical status epilepticus during slow sleep or ESES syndrome including the acquired aphasia. Clin Neurophysiol 2000;111(Suppl. 2):S94-102.

[52] Tassinari CA, Dravet C, Roger J. Encephalopathy related to electrical status epilepticus during slow sleep. Electroencephalogr Clin Neurophysio 1977;43:529-30.

[53] Kramer U, Sagi L, Goldberg-Stern H, Zelnik N, Nissenkorn A, Ben-Zeev B. Clinical spectrum and medical treatment of children with electrical status epilepticus in sleep (ESES). Epilepsia 2009;50(6):1517-24.

[54] Sanchez Fernandez I, Peters JM, Hadjiloizou S, Prabhu SP, Zarowski M, Stannard KM, et al. Clinical staging and electroencephalographic evolution of continuous spikes and waves during sleep. Epilepsia 2012a;53:1185-95.

[55] Sánchez Fernández I, Loddenkemper T, Peters JM, Kothare SV. Electrical status epilepticus in sleep: clinical presentation and pathophysiology. Pediatr Neurol 2012b:47:390-410.

[56] Dalla Bernardina B, Tassinari CA, Dravet C, Bureau M, Beghini G, Roger J Benign focal epilepsy and "electrical status epilepticus" during sleep. Rev Electroencephalogr Neurophysiol Clin 1978;8:350-3.

[57] Dalla Bernardina B, Sgrò V, Caraballo R, Fontana E, Colamaria V, Zullini E, et al. Sleep and benign partial epilepsies of childhood: EEG and evoked potentials study. Epilepsy Res Suppl 1991;2:83-96.

[58] Saltik S, Uluduz D, Cokar O, Demirbilek V, Dervent A. A clinical and EEG study on idiopathic partial epilepsies with evolution into ESES spectrum disorders. Epilepsia 2005;46:524-33.

[59] Kellermann K. Recurrent aphasia with subclinical bioelectric status epilepticus during sleep. Eur J Pediatr 1978;128:207-12.

[60] Halász P, Kelemen A, Clemens B, Saracz J, Rosdy B, Rásonyi G, et al. The perisylvian epileptic network. A unifying concept. Ideggyogyaszati Szle 2005;58:21-31.

[61] Fejerman N. Atypical rolandic epilepsy. Epilepsia 2009;50(Suppl. 7):9-12.

*[62] Halász P, Szúcs A. Sleep, epilepsies, and cognitive impairment. Academic Press Elsevier; 2018.

[63] Di Negri. Electrical status epilepticus during sleep (ESES). Different clinica syndromes: towards a unifying view? Brain Dev 1997;19(7):447-51.

*[64] Lee YJ, Hwang SK, Kwon S. The clinical spectrum of benign epilepsy with centro-temporal spikes: a challenge in categorization and predictability. Epilepsy Res 2017;7(1):1-6.

[65] Rossi PG, Parmeggiani A, Bach V, Santucci M, Visconti P. EEG features and epilepsy in patients with autism. Brain Dev 1995:17:169-74.

[66] Nass R, Devinsky O. Autistic regression with rolandic spikes. Neuropsychiatry Neuropsychol Behav Neurol 1999;12:193-7.

[67] Silvestri R, Gagliano A, Calarese T, Aricò I, Cedro C, Condurso R, et al. Ictal and interictal EEG abnormalities in ADHD children recorded over night by videopolysomnography. Epilepsy Res 2007;75:130-7.

[68] Danhofer P, Pejčochová J, Dušek L, Rektor I, Ošlejšková H. The influence of EEG-detected nocturnal centrotemporal discharges on the expression of core symptoms of ADHD in children with benign childhood epilepsy with centrotemporal spikes (BCECTS): a prospective study in a tertiary referral center Epilepsy Behav 2018;79:75-81.

[69] Tassinari CA, De Marco P, Plasmati R, Pantieri R, Bianco M, Michelucci R Extreme somatosensory evoked potentials (ESEPS) elicited by tapping of hands or feet in children: a somatosensory cerebral evoked potentials study Neurophysiol Clin 1988;18:123-8.

[70] Fonesca LC, Tedrus GM. Epileptic syndromes in children with somatosensory evoked spikes. Clin. Electroencepalogr 1994;25:54-8.

[71] Klink NEC, van't Klooster MA, Leijten FSS, Jacobs J, Braun KPJ, Zijlmans M. Ripples on rolandic spikes: a marker of epilepsy severity. Epilepsia 2016;57: 1179-89.

*[72] Mirandola L, Cantalupo G, Vaudano AE, Avanzini P, Ruggier A, Pisani F, et al. Centrotemporal spikes during NREM sleep: the promoting action of thalamus revealed by simultaneous EEG and fMRI coregistration. Epilepsy Behav Case Rep 2013;1:106-9.

[73] Doose H, Baier WK. Benign partial epilepsy and related conditions: multifactoral pathogenesis with hereditary impairment of brain maturation. Eur J Pediatr 1989;149:152-8.

[74] Koutroumanidis M, Panayiotopoulos CP. Benign childhood partial epilepsies: benign childhood seizure susceptibility syndromes. J Neurol Neurosurg Psychiatr 1993;56:2-5.

[75] Clemens B, Majoros E. Sleep studies in benign epilepsy of childhood with rolandic spikes. II. Analysis of discharge frequency and its relation to sleep dynamics. Epilepsia 1987;28:24-7.

[76] Halász P, Hegyi M, Siegler Zs, Fogarasi A. Encephalopathy with electrical status epilepticus in slow wave sleep - a review with an emphasis on regional (perisylvian) aspects. J Epileptol 2014;22:71-87.

*[77] Nobili L, Ferrillo F, Baglietto MG, Beelke M, De Carli F, De Negri E, et al. Relationship of sleep interictal epileptiform discharges to sigma activity (12$16 \mathrm{~Hz}$ ) in benign epilepsy of childhood with rolandic spikes. Clin Neurophysiol 1999;110:39-46.

[78] Kellaway P. The electroencephalographic features of benign centrotemporal (rolandic) epilepsy of childhood. Epilepsia 2000:41:1053-6.

[79] Terzano MG, Parrino L, Spaggiari MC, Barusi R, Simeoni S. Discriminatory effect of cyclic alternating pattern in focal lesional and benign rolandic interictal spikes during sleep. Epilepsia 1991;32:616-28.

[80] Wickens S, Bowden SC, D'Souza W. Cognitive functioning in children with self-limited epilepsy with centrotemporal spikes: a systematic review and meta-analysis. Epilepsia 2017;58:1673-85.

[81] Neumann $\mathrm{H}$, Helmke F, Thiels C, Polster T, Selzer LM, Daseking M, et al. Development in children with benign rolandic epilepsy of childhood with centrotemporal spikes - results of a current systematic database search. Fortschr Neurol Psychiatr 2016:84:617-32.

[82] Chan S, Pressler R, Boyd SG, Baldeweg T, Cross JH. Does sleep benefit memory consolidation in children with focal epilepsy? Epilepsia 2017;58:456-66.

*[83] Pal DK, Ferrie C, Addis L, Akiyama T, Capovilla G, Caraballo R, et al. Idiopathic focal epilepsies: the "lost tribe". Epileptic Disord 2016;18:252-88.

[84] Avanzini G, Manganotti P, Meletti S, Moshé SL, Panzica F, Wolf P, et al. The system epilepsies: a pathophysiological hypothesis. Epilepsia 2012;53: $771-8$.

[85] Capovilla G, Moshé SL, Wolf P, Avanzini G. Epileptic encephalopathy as models of system epilepsy. Epilepsia 2013;54(Suppl. 8):34-7.

[86] Scheffer IE, Berkovic S, Capovilla G, Connolly MB, French J, Guilhoto L, et al. ILAE classification of the epilepsies: position paper of the ILAE commission for classification and terminology. Epilepsia 2017;58:512-21. -96.

[87] Howell KB, Harvey AS, Archer JS. Epileptic encephalopathy: use and misuse of a clinical syndrome: considerations and hypotheses. Epileptic Disord 2001;3:183-96.

[88] Jehi L, Wyll ie E, Devinsky O. Epileptic encephalopathies: optimizing seizure control and developmental outcome. Epilepsia 2015;56:1486-9.

[89] Blume WT. Pathogenesis of Lennox-Gastaut syndrome: considerations and hypotheses. Epileptic Disord 2001;3:183.

[90] Frauscher B, Bartolomei F, Kobayashi K, Cimbalnik J, van 't Klooster MA, Rampp S, et al. High-frequency oscillations: the state of clinical research. Epilepsia 2017;58:1316-29.

[91] Endoh F, Yoshinaga H, Ishizaki Y, Oka M, Kobayashi K, Ohtsuka Y. Abnormal fast activity before the onset of West syndrome. Neuropediatrics 2011;42: $51-4$.

[92] Tononi G, Cirelli C. Sleep and synaptic homeostasis: a hypothesis. Brain Res Bull 2003;62:143-50

[93] Tassinari CA, Cantalupo G, Rios-Pohl L, Giustina ED, Rubboli G. Encephalopathy with status epilepticus during slow sleep: "the Penelope syndrome". Epilepsia 2009;50(Suppl. 7):4-8.

[94] Beenhakker MR, Huguenard JR. Neurones that fire together also conspire together; is normal sleep circuitry hijacked to generate epilepsy? Neuron 2009 11;62(5):612-32.

[95] Halász P. Are absence epilepsy and nocturnal frontal lobe epilepsy system epilepsies of the sleep/wake system? Behav Neurol 2015:231676. 